\title{
The Application of Virtual Simulation Technology in Studying Vehicle Vibration Characteristics on Random Road
}

\author{
Shuangqing Tang, Zhou Jiang, Qiongqing Bo, Dongwei Zhou \\ College of Mechanical \&Power Engineering Of China Three Gorges University, Yichang, 443002, \\ China
}

Keywords: Road roughness; Vibration characteristics; Reliability; Random road excitation.

\begin{abstract}
This paper think of the car provided by car company as the research object, the filter white noise was used to get some road roughness and create random road excitation, then the entity model of car and four pillar test bench was set up in ADAMS, and next, add random road excitation to the model to carry on the simulation analysis of vibration response and comfort level .So that, the related parameters used to evaluate the car's vibration performance and vehicle ride comfort were get, and it can provide reliable data to study the automobile comfort. All in all, it can make the car's design philosophy turn “design--experiment--improved design---replication---redesign "into "design--simulation---experiment", so the main problems appeared during designing can be solved at the beginning of the design, it is an effective method that shorten the product cycle, reduce production costs, and enhance market competitiveness.
\end{abstract}

\section{Introduction}

As the car was traveling at a high speed, to some extent, the vibration under road excitation can cause discomfort and fatigue driving personnel, and also come about the damage of equipment, especially the suspension system. Therefore, it is particularly important to study the effect of vehicle vibration for comfort and the reliability of on-board equipment by entering the road random excitation.

\section{The Mathematical Description of the Random Road Filtering Method of White Noise}

It was the relevant experiments and experience shown that the road surface roughness is random, stability and continuity, so the stationary random expounds theory can perfectly describe the surface roughness, and it depend largely on PSD fitting function of power spectral density. The filter white noise method was regarding the power spectral density and vehicle speed as known conditions, and the particular filter was obtained through proper mathematical treatment, then it was making the computer random white noise get through the filter that obtained the white noise roughness.

Road as automobile vibration input signal, its main properties was realized by using displacement power spectral density, and formula 1 is fitting equation [1]:

$$
G d(n)=G d\left(n_{0}\right)\left(\frac{n}{n_{0}}\right)^{-w}
$$

When researched the vehicle vibration response caused by random road, the space power spectral density require to turn into time power spectrum density function on account of the input signal is received under the influence of speed and road roughness, the“ $f=n u$ "was general transformational , and also, f--input; u--speed of the vehicle, after the Laplace transform, it can get equation(2):

$G d(f)=\frac{G d(n)}{u}$

Making (2) to mathematical transform, it can get equation (3)

$$
G d(f)=\frac{1}{u} G d(n)=G d\left(n_{0}\right) n_{0}{ }^{2} \frac{u}{f^{2}}
$$


The Virtual Prototype Model of a Car Currently, the cars designed by mainstream car manufacturers in the domestic and overseas were principally made of basic body subsystem, power transmission subsystem, MacPherson suspension frame system, torsion beam rear Suspension frame system and steering subsystem. Therefore the full vehicle model can be obtained by assembling each subsystem, the primary data provided by the company was shown in table 1 :

Modeling were using ADAMS standard module, according to the above parameters, and combining with the model drawings,[2] the cars each subsystem was completed one by one under the condition of certain equivalent and simplified, then assembled into the whole car model as required ,the final model was shown in figure 1.

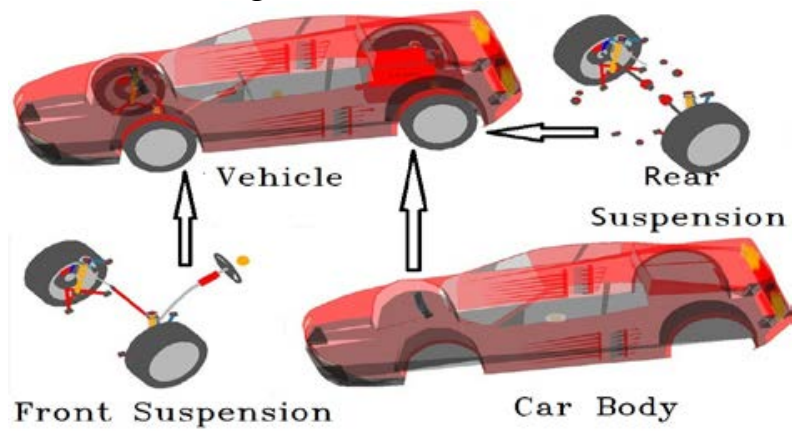

Fig 1 the vehicle model and subsystem model

Table 1 the primary data of car

\begin{tabular}{|c|c|c|c|c|}
\hline \multicolumn{3}{|c|}{ Car status } & Reorganize and outfit status & $\begin{array}{l}\text { Full load } \\
\text { condition }\end{array}$ \\
\hline \multicolumn{3}{|c|}{ Total mass (kg) } & 1120 & 1450 \\
\hline \multirow{6}{*}{$\begin{array}{l}\text { The wheel load } \\
\text { distribution }\end{array}$} & \multirow{4}{*}{ Wheel load } & $\begin{array}{c}\text { Front wheel } \\
\text { (left) }\end{array}$ & 326 & 384 \\
\hline & & $\begin{array}{l}\text { Front wheel } \\
\text { (right) }\end{array}$ & 320 & 378 \\
\hline & & $\begin{array}{l}\text { Back wheel } \\
\text { (left) }\end{array}$ & 216 & 336 \\
\hline & & $\begin{array}{l}\text { Back wheel } \\
\text { (right) }\end{array}$ & 210 & 332 \\
\hline & \multirow{2}{*}{ Axle load } & Front axle & 676 & 786 \\
\hline & & Back axle & 442 & 677 \\
\hline \multicolumn{3}{|c|}{ The center of mass right (mm) } & -8 & 2 \\
\hline \multicolumn{3}{|c|}{ Height of center of mass (mm) } & 556 & 592 \\
\hline \multicolumn{3}{|c|}{ Front axle of mass center moment of front axle (mm) } & 990 & / \\
\hline
\end{tabular}

\section{The Equivalent and Addition of Random Road Surface}

In order to take a full consideration to the actual condition of road surface, the experience road model was based on the classic white noise model and a combination of many different types of pavement parameters, and the functional relation between road surface 's power spectral density and spatial frequency space was as follows:

$$
G_{d}(n)=G_{e}+\frac{G_{s}}{(2 \pi n)^{2}}+\frac{G_{a}}{(2 \pi n)^{4}}
$$

According to the parameter in table (2), choose corresponding Ge, Gs, Ga can construct practical road excitation to meet different road conditions.

It was the present situation what mostly road were asphalt pavement that choose standard of asphalt pavement as the random road excitation to proceed simulation , then put the asphalt roadbed coefficient in table (2) into formula (4) can get the function of pavement profile, in the next moment, add this function as the input signal to the car on the pillar and complete the simulation model with random road, it was shown in figure (2): 
Table 2 The Pavement parameters

\begin{tabular}{cccccc}
\hline $\begin{array}{c}\text { Road } \\
\text { surface } \\
\text { type }\end{array}$ & $\begin{array}{c}\text { Asphalt } \\
\text { pavement }\end{array}$ & $\begin{array}{c}\text { Coarse asphalt } \\
\text { pavement }\end{array}$ & $\begin{array}{c}\text { Smooth cement } \\
\text { concrete } \\
\text { pavement }\end{array}$ & $\begin{array}{c}\text { Cement } \\
\text { concrete } \\
\text { pavement }\end{array}$ & $\begin{array}{c}\text { Rough cement } \\
\text { concrete } \\
\text { pavement }\end{array}$ \\
\hline Ge & 0 & 0.003 & 0 & 0.1 & 0.1 \\
Gs & 12 & 20 & 1 & 20 & 35 \\
Ga & 0.17 & 0.20 & 0 & 0.25 & 0.3 \\
\hline
\end{tabular}

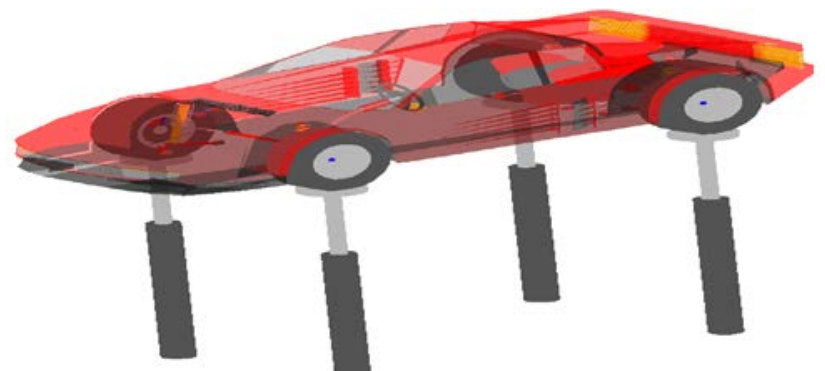

Fig 2 the model of vehicle with four pillar equivalent pavement

\section{The System Simulation Analysis of the Vehicle}

In view of the road excitation of randomness, in order to get a better simulation results, the step5 function was used as speed input, which use five times polynomial to approximate hessian step function, it has the Characteristics "a continuous one, the second derivative" can guarantee cars start stage without any impact phenomena under the affect of road excitation[3].

$$
\left.\operatorname{Step} 5\left(x, x_{0}, h_{0}, x_{1}, h_{1}\right)=\left\{\begin{array}{c}
h_{0} \rightarrow x \leq x_{0} \\
h_{0}+\left(h_{1}-h_{0}\right)\left[\left(x-x_{0}\right) /\left(x_{1}-x_{0}\right)\right]^{3} \\
\left\{10-15\left[\left(x-x_{0}\right) /\left(x_{1}-x_{0}\right)\right]+6\left[\left(x-x_{0}\right) /\left(x_{1}-x_{0}\right)\right]^{2}\right\} \\
h_{1} \rightarrow x \geq x_{1}
\end{array}\right\} x_{0}<x<x_{1}\right\}
$$

The vehicle's engine used $75 \mathrm{kw}$, engine idle speed is $800 \mathrm{r} / \mathrm{min}$, the vehicle have 7 seconds to reach regulation speed, and the speed keep in $70 \mathrm{~km} / \mathrm{h}$, the total

Simulation time is $10 \mathrm{~s}$.

Vehicle vibration is inevitable when the vehicle is in motion,so it will be a strong conviction that the horizontal floating angle of suspension system,as well as the contact force on the front and rear wheels to study the characteristics of vehicle vibration,the change curves were shown in figure(3)(4) :

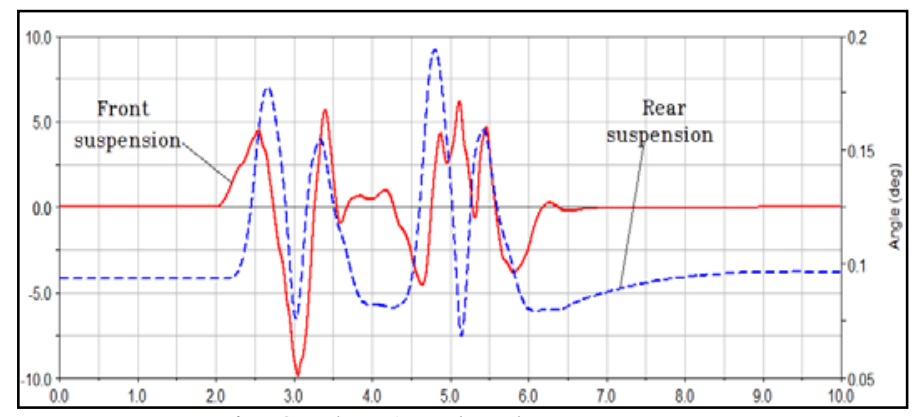

Fig 3 The Angle change curve

Car's ride quality is directly related to occupant comfort, ${ }^{[4]}$ and involves the automobile power performance and fuel economy, also affect the service life of parts and components, so it is an important performance index to gain supremacy in global market. Car's ride comfort can be evaluated by the acceleration power spectrum density function and weighted root mean square value. The acceleration and acceleration power spectrum density function curve on three directions $(\mathrm{x}, \mathrm{y}, \mathrm{z})$ of driver's seat centre were shown in figure (5) (6): 


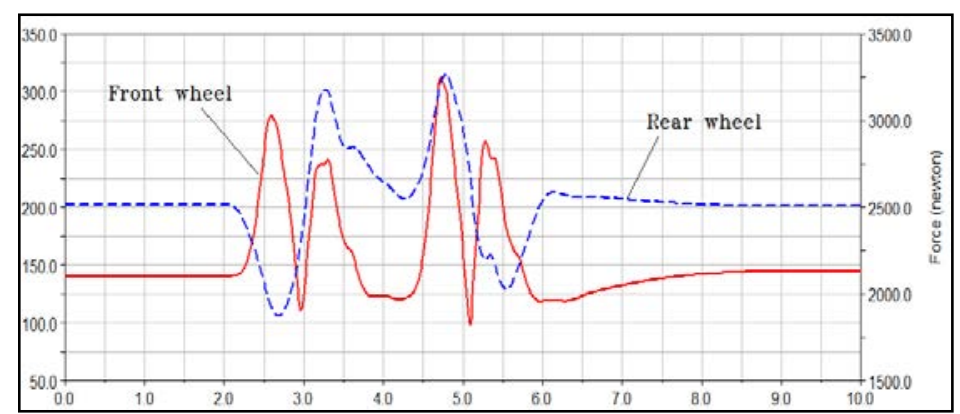

Fig 4 The Contact force change curves

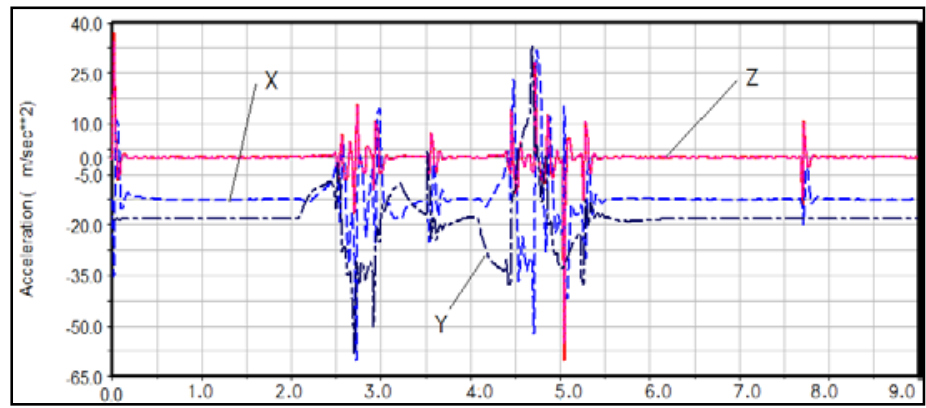

Fig 5 the acceleration curve of driver seat

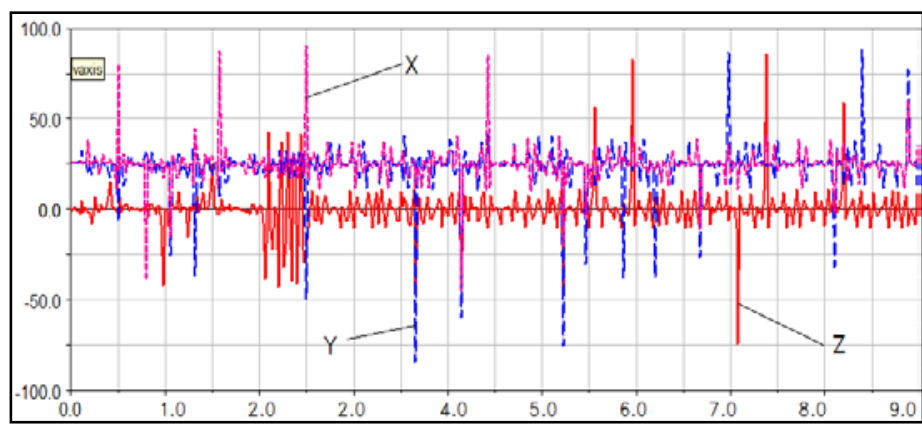

Fig 6 the acceleration power spa strum density curve of pilot seat

According to regulation of GB/T 4970-4970 "random driving comfort ability test method", the weighted acceleration of driver's seat can be obtained by the formula in table(3) .

Table 3 the formula of weighted acceleration

\begin{tabular}{cc}
\hline$a_{w}$ & $w_{z}(f)$ \\
\hline$a_{w}=\sqrt{\int_{0}^{70} w^{2}(f)} \bullet G(f) d f$ & $w_{z}(f)=\left\{\begin{array}{c}0.5 \sqrt{f(0<f<4)} \\
1.0(4<f<8) \\
8 / f(f>8)\end{array}\right\}$ \\
$w_{y}(f)$ & $w_{x}(f)=\left\{\begin{array}{c}1.0(0<f<2) \\
2 / f(f>2)\end{array}\right\}$ \\
\hline$w_{y}(f)=\left\{\begin{array}{c}1.0(0<f<2) \\
2 / f(f>2)\end{array}\right\}$ & $G(f)$ \\
\hline$a_{w 0}$ & $G d(f)=\frac{1}{u} G d(n)=G d\left(n_{0}\right) n_{0}{ }^{2} \frac{u}{f^{2}}$ \\
\hline$a_{w 0}=\sqrt{\left(1.4 a_{x w}\right)^{2}+\left(1.4 a_{y w}\right)^{2}+\left(a_{z w}\right)^{2}}$
\end{tabular}

According to the regulations of the GB9652-86, the comprehensive acceleration were obtained in $10,20,30,40,50,60 \mathrm{~km} / \mathrm{h}$ by using the above-mentioned weighted formula, as shown in the following table (4) : 
Table 4 the car's acceleration under different speed

\begin{tabular}{cccc}
\hline$V(\mathrm{Km} / \mathrm{h})$ & 10 & 20 & 30 \\
$W a\left(\mathrm{~m} / \mathrm{s}^{2}\right)$ & 13.38 & 15.89 & 20.67 \\
$V(\mathrm{Km} / \mathrm{h})$ & 40 & 50 & 60 \\
$W a\left(\mathrm{~m} / \mathrm{s}^{2}\right)$ & 28.95 & 40.32 & 50.67 \\
\hline
\end{tabular}

Refer to relevant indicators comfort ability, it was known that human body health will be influenced when the driver's maximum response acceleration of more than $43.02 \mathrm{~m} / \mathrm{s}^{2}$, howevery it will not have any harm when less than $31.44 \mathrm{~m} / \mathrm{s}^{2}$, and between the two will have certain harm to the health. From the above simulation data ${ }^{[5]}$, it shown that the driver have certain uncomfortable due to the vehicle vibration when the cars were speeding up on random road; the driver will start to appear bad feelings when the car speed was more than $60 \mathrm{~km} / \mathrm{h}$, and when more than $80 \mathrm{~km} / \mathrm{h}$, the driver's subjective feeling was rather to adapt.

\section{Conclusion}

By using Adams virtual simulation environment, and thinking of random road excitation based on white noise fitting method as the input signal and constraints to complete the simulation analysis of vehicle vibration characteristic and comfort ability, it can get the following conclusions:

With the development of virtual product, virtual manufacturing technology is gradually mature, so the computer simulation technology is widely used, and digitized virtual prototype technology has been an important way to to shorten research cycle, lower development costs, improve the quality of product design and manufacturing.

Adams software make the dispersed components design and analysis techniques close togetherr,so it is convenient to establish dynamics model of the vehicle's multi-body system, and provide an effective way to understand the product performance and evaluate the products reliability, to make the main problems in the design process will be solved at the beginning of the design based on digital prototype technology, especially in the consideration of dynamics and control integration problems, such as ABS, TCS, multibody system dynamics will show a greater role.

Its analysis results not only can provide a strong theoretical basis to evaluate the comfort, stability, security and reliability of car, but also, to some extent, can Put forward some rationality improvement opinions for optimizing and designing the automobile structure.

\section{References}

[1]LIN Min, Zhang Xiang-wei, Cheng Si-yuan. Simulation of three-dimensional road based on pseudo excitation method [M].Machinery Design \& Manufacture, 2012, 2(2): p. 84-86

[2]CUI Yuan-xin. Modeling and Ride Comfort Simulation of a FF Car Based on Virtual Prototyping Technology [D].Chang Chun: Jilin University, 2013, 4

[3]LI Gui-kang. Simulation and Parameter Optimization Design of Military Vehicle Hydro-Pneumatic Suspension [D].Chang Chun: Jilin University, 2013, p.6

[4] ISO 2631-1997, Mechanical Vibration and Shock-Evaluation of Wuman Exposure to Whole-body Vibration-Part1: General Requirements[S].

[5]Hillary B, Ewins D J. The Use of Strain Gauges in Force Determination and Frequency Response Functon Measurements. Proceedings of the 2nd international Modal Analysis Conference Florida, USA, 1984: p.627 634. 